\title{
Project activity in the sphere of digital technologies
}

\author{
E.P. Panova*1, N.R. Saenko ${ }^{2}, P . S$. Volkova ${ }^{3}$, E.V. Bobyreva ${ }^{4}$ and V.V. Kortunov ${ }^{5}$ \\ ${ }^{1}$ Moscow Polytechnic University, Bolshaya Semyonovskaya str., 38, Moscow, 107023, Russian, panova_ep@mail.ru \\ ${ }^{2}$ Moscow Polytechnic University, Bolshaya Semyonovskaya str., 38, Moscow, 107023, Russian, rilke@list.ru \\ ${ }^{3}$ Krasnodar Higher Military School named after General of the army S.M. Shtemenko, Krasina Street 4, Krasnodar, \\ 350063, Russian, polina7-7@yandex.ru \\ ${ }^{4}$ Volgograd State Social and Pedagogical University, Lenin, d. 27, Volgograd, 400066, Russian, new_life@mil.ru \\ ${ }^{5}$ Russian State University of Tourism and Service, Glavnaya Street 99, dp.Cherkizovo, Pushkinsky district, Moscow, \\ 141221, Russian, kortunov@bk.ru
}

\begin{abstract}
The article considers the problems that arose in the situation when the world's system of education has been forced to transfer into distance learning mode because of the pandemic. For the first time mankind had got an experience when it became necessary to abandon traditional training. In such situation, it was possible to continue providing education both in schools and in the universities due to the advantages that "digitalization" of education carries, though a number of shortcomings that both teachers and students faced were also revealed. Empirical experiment allowed to find out that distance education has significant shortcomings which affect both quality of knowledge and physical and mental health of people as well as socio-cultural adaptation and socialization of foreign students. Abandonment of traditional education in favor of distant one carries significant losses in the quality of education and, as a result, decreases the ability to create a harmonious and comprehensively developed personality. Authors of the article come to the conclusion that distance education should be used as an additional form of education in comparison to basic one (traditional), that is, it can provide positive results only in the complex (traditional plus distance).
\end{abstract}

\section{Introduction}

In our days question of project activity is relevant in the framework of higher school education, especially in the humanitarian sphere, since this area is outside the zone of material and technical capabilities, rather it is a sphere of ideas, a sphere of theoretical knowledge making attempts to understand surrounding world. Perhaps that is why methodology of teaching foreigners Russian as a foreign language at the preparatory departments of Universities doesn't consider possibility of using project activities as a successful method of teaching. At the initial stage of teaching a foreign language project methods cannot be used because of the language barrier, as foreign students have very poor command of Russian. Though in the second term of the first year it is possible to introduce various types of project activity. The following problems arising in the process of applying project activity method at the preparatory faculty can be highlighted: complex process of social adaptation, difficulty in intercultural communication skills formation.

Nevertheless, during the second term of the first year is not only possible but just necessary for a teacher to introduce a project activity method as it helps students to overcome arising problems more successfully: including problems of sociocultural and intercultural adaptation, improving cognitive and communicative skills, increasing creative activity and the level of motivation and, as a result, improving general level of language skills. E.G. Krylov in the article "Peculiarities of teaching foreign students engineering disciplines" raises the question of using method of projects in the process of teaching foreigners, since this technology allows to increase motivation to study Russian as a foreign language. E.G. Krylov suggests to stimulate motivation using the project method (foreign students are invited to carry out projects on a voluntary basis). During such classes, students can be invited to complete a course project both in sciences and humanities, participate in the Olympiads in different subjects, to hold festivals and competitions, to participate in creative projects (theater and concert productions), make a report or a presentation at the conference, etc.

However, in the present situation prevailing in the world - self-isolation because of COVID-19 - it has become impossible to organize project activities in the system of traditional education. Therefore, an attempt was made to transfer project activities into a remote format. And as not all project activities can be carried out in a digital mode, it was decided to select several projects and conduct them on a competitive basis. Due to the fact that at present circumstances we had to abandon traditional training, organization of professional

\footnotetext{
*Corresponding author: panova_ep@mail.ru
} 
activities at both sites (Moscow Polytechnic and Volgograd State Technical University) was arranged distantly in two ways: independently and in the on-Line class. Such experience of organizing training - when work was transferred into the remote format and traditional training had to be abandoned - was received by the educational world for the first time.

\section{Problem Statement}

The problem of the study is to justify the possibility/impossibility of project activity in the distant learning (e-leaning) mode, whether it is possible to form students' professional skills, critical and creative thinking, independent skills in the conditions of digitalization.

\section{Research Questions}

Is it a myth or reality to organize successful and effective training of foreign students in the sphere of project activities with the help of digital technologies at the initial stage of study?

Is it possible to use method of cooperation during project activities in the process of distant learning?

How productive it is to develop a person in different forms of activities in the process of distant learning performing project activities?

\section{Purpose of the Study}

To reveal the results of efficiency/inefficiency of student's project activity organization using digital technologies in comparison to traditional education, as well as to describe the methodology of various types of projects aimed at developing critical and creative thinking, professional skills and various aspects of human activity.

\section{Research Methods}

The methodological basis of the study is made up of the principles and provisions of the systemic, structuralfunctional and comparative-typological approaches.

An important methodological guideline in this study is the works of Russian developers of distance learning V. Samoilenco, T.V. Tretyakova, who write about the modification of modern higher education through distance learning [1-2]. Ideas about the modernization of higher education are developed in works by Ö.H. Kuzu [3]. An in-depth analysis of the transformation of higher education using digital technologies is found in the works of L. Seres et al [4]. C. Dexeus [5] writes about the revolutionary process in the higher education system, which is happening today with unprecedented speed. K. Sandkuhl spoke about the consequences of the transformation of the traditional education system [6]. Akhmetova's observations on the use of digital technologies in the sphere of inclusive education are of great interest [7]. Making various fields of activity in higher education digital is also being actively discussed in modern pedagogy [8-9].

Scientists from different countries, such as Collins, A., \& Halverson, R., Thiele, AK, Mai, JA, \& Post, S. believe that modern students are a new generation or "network generation", which focuses on new forms of education. Digitalization of the educational process of higher education is a natural phenomenon for modern students, they give preference to it, as they consider it more natural, adequate and goal-oriented [10-11].

M. Brown claims that digital teaching methods have been added to traditional face-to-face education, which has led to the fact that the methods are now mixed / hybrid [12].

Almaraz-Menendez, F., Maz-Machado, A., \& LopezEsteban, C. correctly note that distance education has become more flexible, accessible [13], thus, all scientists come to the conclusion that modern education needs to be reshaped and adapted to meet the needs and requirements of a new "network" generation.

\section{Findings}

As part of the study, two experiments were conducted with foreign students and teaching staff of Volgograd State Polytechnic University and Moscow Polytechnic University. The first experiment was aimed at establishing effectiveness/inefficiency of education organization using digital technologies. To form a certain picture of success/failure of the process of teaching Russian as a foreign language in the conditions of distant learning (self-isolation) using digital technologies 154 students as well as 27 teachers had been chosen to participate in the experiment. The experiment made it possible to form the following opinion - to what extent foreign students managed to perceive the material in the process of distant education (DE) and to what extent distant learning using digital technologies was effective/ineffective as well as how much the quality of education using DE increased/decreased.

The questionnaire included the following groups of questions:

$95 \%$ of recipients understand material better in class; $67 \%$ of recipients replied that they did not understand material well enough in the process of distant learning.

$58 \%$ of recipients responded that process of distant learning affects the quality of education but not much, 42 $\%$ responded that it affects the quality negatively. Students' knowledge on the subject has become worse.

The language cannot be learned distantly - answered $69 \%$ of respondents; it is possible to learn it but not well enough - responded $41 \%$.

The length of classes conducted in digital mode is significantly reduced: only $40 \%$ of students can study 2 3 hours a day, $28 \%$ can study 4 hours a day and $12 \%$ can be engaged in studies 5 hours a day.

Recipients replied that the main difficulty of distant learning is that at the initial stage of language learning foreign students have poor command of the Russian language and therefore they have language difficulties 
(language barrier) studying online. Also, distant learning does not create conditions for communication, and besides it is possible to use much more methods and techniques of teaching students in the classroom; a student manages to do more tasks and understands material better and deeper when in the classroom. Students answered that it was "better for them to study in the classroom; they had much more conversational practice events".

In addition to the above-mentioned problems, students also mentioned that online learning process leads to the decrease of their health conditions, besides a whole range of psychological difficulties arises; the reason for their complaint had also become the lack of language environment during distant learning, since it is the language environment itself that contributes to the development of communicative skills; they indicated that they had no opportunities to study at home as they often have technical failures with the Internet and problems of technological character in general. The questionnaire showed that there was another significant drawback that students mentioned and that was the lack of direct contact with a teacher. This fact causes a lot of difficulties for students in understanding and assimilating material, leads to decrease of the quality of fulfilled tasks and exercises, to the efficiency of education, to deterioration in control over student's activities and to decrease of interest in study in general. All these data affect the quality of knowledge of the Russian language, since at the initial stage of studying Russian as a foreign language foreign students don't have enough practical skills to study language all by themselves (independently).

Foreign students also noted that distant education narrows consciousness to the size of a computer screen; experience has shown that it is impossible to socialize (since there is no live communication) and to get sociocultural adaptation, since there is no way to work in a team. It is impossible to get overall development of creative and critical thinking, since a huge number of tasks and types of creative work students get can be realized neither during classes nor during activity on the platform. So, for example, "during the process of translation [...], some difficulties connected not only with cultural differences but also with differences in principles of functioning of phonetic, grammatical, syntactic, lexical systems of the language arise" [14]; and during distant learning such forms of work become even more complicated and it is practically impossible to fulfill them.

Thus, summing up everything mentioned above, it can be concluded that abandoning traditional education and replacing it with distant one leads to a deterioration in the quality of education, since "Digital technologies only aggravate the process of separating people, make society more fragmented and individualistic. Not interacting with each other people find themselves outside the framework of socialization and become increasingly intolerant to each other. Understanding as a process of interaction in the frameworks of presently formed communication in the classroom - studentstudent or pupil-student - begins to collapse and that destroys teaching process in general, doing it more and more low-quality and unskilled process" [15]. In the process of distant education, it is possible to get only some basic skills; in the framework of digitalization formation of comprehensively developed and educated person becomes impossible. Distant learning, despite its advantages (transparency, budgeting, flexibility, time and space release, territorial independence, accessibility), can function only as additional, concomitant form of education being combined with traditional one.

To from an overall picture of success lfailure assessment in teaching project activities using digital technologies in conditions of self-isolation an empirical study was also conducted among foreign students aged 18-28 (73 people participated in the experiment) of Moscow Polytechnic University and Volgograd State Technical University of preparatory faculties. During the experiment an attempt was made to find out in what way this form of project activities organization (using distant technologies) contributes to the development of creative skills, independence in organization of educational process, cognitive and communicative skills, critical and creative thinking and the ability to work both independently and in a team. "Project activity helps a teacher to solve a very important task: to make each student involved into active cognitive work. The project method helps students to learn how to set goals and find means and ways to achieve them. It should be noted that project activity has a certain limitation in the terms of time and resources, which, in its turn, enhances its educational potential", point out Semikina Yu. G. \& Semikin D. V. [16]. Thus, project activity presents an instrumental level of organizing students' activities because this type of activity makes an accent on creation of a material objects. "In order such structure becomes possible students must make their own efforts to search, process and analyze data, plan their actions and communicate with various partners. Since such activities usually go beyond individual actions, they require team work. Further we will mainly talk about a projectoriented approach emphasizing that it necessarily includes problematization" [17].

For a long time it was believed that project activity was impossible at the initial stage of teaching $\backslash$ studying Russian as a foreign language. However, today, as a part of project activity at the preparatory faculty of the University a number of events are organized, such as: student conferences, Olympiads, presentations, essay competitions, creative competitions, debates, theater plays, literary events, festivals, linguistic tourism, etc. Such events expand intercultural communication, help student to adapt socially, increase students' cultural and aesthetic level, develop creative thinking, increase motivation, improve cognitive and communicative skills, teach to work in groups under teacher's guidance, form skills of self-work, etc. All these projects implemented at the preparatory faculty have a common methodological basis: 1) training within these projects is based on mutual activities; 2) activities are based on a student-centered approach; 3 ) final result of such activity is creation of a complete product; 4) work on the project 
takes place in a team (group), a teacher just directs and advises, helping students to set the goal and problem of a project and he also sets tasks.

Thus, taking into account the results of the first experiment, it is possible to speak about the barriers that can be come across in the process of introduction of digital technologies into education system. Such barriers can prevent introduction of project activities into the educational process through digitalization. So students can experience difficulties in perceiving educational material working in a distant mode (cognitive barriers), software language does not coincide with the native language of a foreign student (content barriers), students may not be ready to study distantly, and there may be different reasons for that, but the main reason is didactic [18]. In the process of education technical problems may arise, that is, both students and teachers may lack the necessary equipment (laptops, computers, etc.). In this case, financial barriers arise (costs of the latest technologies and software). An equally important problem is the problem of "digital literacy" of teachers. All these barriers must be taken into account when implementing project activities by means of digitalization.

In this respect it is necessary to mention psychological and pedagogical types of competence a student must have studying distantly. The most important types of competence are softskills competencies (such competences as ability to work in a team, to communicate, to adjust quickly, ability to manage your own psychological and emotional state, to listen, to talk and to come to an agreement) [7]. In the process of introduction project activity using digital technologies the following types of psychological and pedagogical competence were taken into account: cognitive (desire to increase psychological and pedagogical knowledge, desire to self-education), motivational (motivation for successful professional activity, existence of professionally important personal qualities), reflexive and fascilitative (situation, ability to control yourself), informative and communicative (ability to work with information, ability to build successful communication). These very competences of students are formed by the second semester of study at the preparatory stage of teaching Russian as a foreign language; that is why the decision was made to introduce design activities in the distant mode in the situation of self-isolation.

In the process of distance learning not all types of work that are used in project activity in the process of traditional education can be transferred into a distance form. The decision was made to organize project activity in the following types of work: to create a video, a presentation, a greeting card, a poster with a hashtag, a symbolic emblem with some text, to write an essay, to take a photo and come up with its name and history. Such projects can really be implemented in a digital format. Besides, it is important to note that in order to increase the level of students' motivation to study distantly, it was decided to implement the method of project activity on a competitive basis, while each project should be connected with one topic, that is, to come up with and develop such thematic blocks that would be closely connected with the history and culture of Russia.

Essay competition helps foreign students to master written speech, so in the second semester it is possible to implement such project. In this case, students learn to work with information, analyze new material, to prove their point of view, to express their thoughts in written form correctly, to develop creative and critical thinking. Reading competition, competition "my favorite national dish", competition of stories with a presentation about your country can be shown in the form of a video. Such activity presents a good methodological basis to organize project activity in a format of distant learning process. Self-production of a video on a given topic helps to develop communicative skills such as speaking, writing, reading, auditing, because before creating a project a student needs to collect material, to write a story and then to prepare an oral message to be recorded. Such video can be filled with motion in the form of multimedia, elements of text which become animated with the help of graphics, color and musical accompaniment.

Creative projects, such as a contests of postcards, contests of posters with hashtags, contest of emblems, contest of photography, drawing contest develop not only communicative skills (writing and reading), but also introduce students to the culture and history of Russia. Students not only get acquainted with the symbols and heraldry of our country and with its history, but also get to know peculiarities of our culture and etiquette. Students also practice writing skills as in these projects they need to present a text of congratulation of either a poetic or a prose character. At the stage of works checking a jury that evaluates projects according to predetermined criteria is formed, thus achieving transparency and objectivity of control.

In order to evaluate the results of work in a digital format it is necessary to summarize objective results of the experiment. The purpose of the heuristic experiment conducted among foreign students was made in the attempt to identify the advantages and disadvantages of organizing project activities for foreign students in a digital mode. During the survey the following advantages were found: $98 \%$ of students took part in projects and showed great interest in it, $99 \%$ of students wrote that such type of work helped to increase their level of knowledge of Russian, their communicative and cognitive skills, that is, students noted that they got new knowledge of vocabulary and grammar, improved skills working with Internet-bases in Russian. 99 \% of students replied that process of project preparation was quite difficult for them, it took a lot of time, it required deep knowledge of the language, but at the same time it expanded their ideas about aesthetic, cultural and sociopolitical characteristics of our country (students got an idea about national and state holidays of our country, our national cuisine, Russian cinema, cartoons, literature, they learnt socio-political and geographical realities of our country).

Perhaps that's why students answered (99\%) that work on the project allowed them to gain extensive 
knowledge in the field of Russian history, culture and art. They replied that participation in the projects in general helped them to understand and therefore love Russian culture more, to expand the vocabulary (they learnt a lot of words with specialized meaning) and their knowledge in grammar. They learnt Russian better, increased their level of motivation, managed to get to know more not only about Russian culture, but also of grammar and syntax of the Russian language.

Answering the task "Write 2-3 positive characteristics of distant participation in the events", students noted such advantages of distant learning as transparency and the possibility of covering great geographical and territorial spaces thanks to Internet resources (you do not need to spend time traveling, participants living in different parts of the city and country can take part in a project at any time, conduct assessments and save time sending documents). So called "erasing boundaries".

Students also replied that participation in the project activity, despite its remote nature, helped them to become more confident, to believe in their own power, helped them to fill their free time with an interesting business, and contributed to the acquisition of lifeimportant knowledge and practical skills.

To the question: "Are there any differences between face-to-face and distant participation in such events? and What is the difference between face-to-face and distance participation?" - $98 \%$ of recipients replied that, in the projects that take place in a real-life format there is an amazing atmosphere, on the one hand, which allows students to take their business seriously and, on the other hand, an atmosphere of a holiday is created. Process of project preparation is better and longer which leads to higher quality results. "All participants can directly contribute to the development of events, comment and evaluate final result obtained due to the participation in the project, make decisions, create a festive atmosphere of the event itself". In the process of full-time participation in the projects, students can work in teams or groups which allows to implement method of creation and further on allows students to exchange ideas achieving better results working in groups. During faceto-face participation an atmosphere of joy, unrest, competitiveness and, at the same time, peace and unity is created - people get valuable experience of empathy in creativity and joint activity.

$84 \%$ of respondents believe that participation in a face-to-face event is more difficult and require more responsibility from psychological and linguistic point of view as assessment of work on the project and assessment of final result is presented collectively, to the group, and is more objective than during correspondence learning.

$89 \%$ of recipients replied that if a teacher consulted them in person, in a live format, they would have managed to prepare projects of higher quality.

In the process of interviewing recipients, the negative aspects of joint project activities using digital technologies were pointed out: weak technical support for both students and teachers, enterprises will have to install equipment and software that can be expensive for small and medium-sized workshops; it is also difficult to determine the degree of students' independent participation in the project, lack of a festive atmosphere, lack of emotions of joy, lack of healthy cooperation that are formed in the process of team work. Also, as a main drawback the recipients pointed inability to participate in the project in the living. Also, vast majority claimed that there are such shortcomings in the organization of distant learning as poor technical level of communication and poor technical preparation to distant learning both of students and universities.

When asked: «have you learne, thanks to remote participation in the competition, to communicate with other people, have you become more sociable?» - 98 per cent of recipients replied that they either had to communicate only with their teacher via Skype technologies or to solve all the arising problems all by themselves. In the process of work on the project students were deprived of mutual cooperation and mutual communication which excluded possibility of implementing socio-cultural adaptation, did not teach them intercultural communication skills. $100 \%$ of respondents wrote that they did not find new friends participating in the project activity distantly.

\section{Conclusion}

In the conclusion we would like to point out that teaching foreign students Russian as a foreign language using distant technologies significantly reduced their level of knowledge and, despite the fact that introduction of project activities became possible in digital format, nevertheless, such work did not lead to effective results. The decline in the quality of education is due to the emergence of a number of barriers, primarily cognitive, communicative, financial and didactic ones. It is also necessary to mention problems foreign students have in the sphere of socialization and sociocultural adaptation. Therefore, in the future it is necessary to take into account that distant education is possible only in combination with traditional one and only in tandem with traditional education it can lead to food results.

\section{References}

1. V. Samoilenko, International Journal of Nursing Scenes, 4, 343-344 (2017)

2. T.V. Tretyakova, E.Z. Vlasova, E.A. Barakhsanova, M.S. Prokopyev, \& M.A. Integrating Engineering Education and Humanities for Global Intercultural Perspectives. IEEHGIP (2020)

3. Ö.H. Kuzu, Higher Education in Russia, 29(3), 923(2020)

4. L. Seres, V. Pavlicevic, \& P. Tumbas, 12th International Technology, Education and Development Conference (INTED2018) Conference Proceedings, 9491-9497 (2018)

5. C. Dexeus, The Deepening Effects of the Digital Revolution. In E. Fayos-Solá, C. Cooper (Eds). The Future of Tourism: Innovation and Sustainability (2019). 
6. K. Sandkuhl, \& H. Lehmann, In A. Rossmann, A. Zimmermann (Eds). Digital Enterprise Computing. Bonn: Gesellschaft für Informatik, 49-60. (2017) URL: https://dl.gi.de/handle/20.500.12116/119;jsess ionid=1A142A0814932BBEF0EE7D38FA224CF9 [in Ger] (date of access: 12.02.21)

7. D.Z. Akhmetova, T.S. Artyukhina, M.R. Bikbaeva, I.A. Sakhnova, M.A. Suchkov \& E.A. Zaitseva Higher education in Russia 29 (2), 141-150 (2019)

8. V.A. Lazarenko, P.V. Kalutskiy, N.B. Dremova, \& A.I. Ovod, Higher Education in Russia 29(1), 105$115(2020)$

9. V.A. Starodubtsev, \& I.V. Ryashentsev, Higher Education in Russia 29 (4), 63-72 (2020)

10. A. Collins, \& R. Halverson, Rethinking Education in the Age of Technology: The Digital Revolution and the Schools. (New York: Teachers College Press. 2009)

11. A.K. Thiele, J.A. Mai, \& S. Post, Journal of Physical Therapy Education 28(1) 80-93(2014)

12. M. Brown, Educause Review 50(4), 16-28 (2015)

13. F. Almaraz-Menendez, A. Maz-Machado, \& C. Lopez-Esteban, International Journal of Advanced Research 4(10), 2284-2296 (2016)

14. E.P. Panova, VolgGTU (Volgograd, 2013)

15. E.P., Panova \& N.R. Saenko, Service plus, 94-102 (2020)

16. Yu.G., Semikina \& D.V Semikin, Business. Education. Law., (3) 399 - 403 (2019)

17. V.S. Khamidulin, Higher education in Russia 29(1), 135-149 (2020)

18. G. Marci-Boehncke \& T. Vogel 12th International Technology, Education and Development Conference (2018) 